\title{
The Domestic Politics model
}

Company-specific differences between ExxonMobil, Shell and Statoil can shed light on differences in their climate strategies to only a limited extent. Chapter 4 revealed that company-specific features with implications for climate strategies are marked more by similarities than differences. The CA model is also incapable of explaining changes in corporate climate strategies.

We explore whether the national political contexts in which the companies operate prove more capable of explaining corporate climate strategy. As shown in chapter 2, there is reason to believe that the relationship between the companies' home-base countries and corporate strategies is important. This link will be analysed in a comparative perspective with the guidance of the Domestic Politics (DP) model. The DP model highlights the extent of social demand for environmental quality, the type of climate policy supplied by the government, and the way in which political institutions link supply and demand, that is, the relationship between state and industry. The basic assumption is that differences in corporate climate strategies can be traced back to differences along these dimensions in the home-base countries of the companies. More specifically, we assume that a high social demand, supply of an ambitious climate policy, and a link between state and industry characterised by cooperation and consensus seeking will lead to a proactive strategy. Conversely, a low social demand, a lenient climate policy, and political institutions that promote conflict and imposition are expected to lead to a reactive climate policy.

In this chapter, we focus on the Netherlands, Norway and the 
US, which are the main home-base countries for Shell, Statoil and ExxonMobil, respectively. Although the oil industry is global and potentially affected by all countries in which it operates, multinational oil companies are closely tied to a specific home-base country. The significant differences observed in climate strategies between Shell, ExxonMobil and Statoil are thus possibly linked to political contexts in which these companies have their historical roots, have located their headquarters and have their main activities.

This chapter is structured as follows. In the first section, we shall explore social demand for climate policy, while the second section will take us to the actual supply of climate policy. The third section is concerned with the political institutions linking supply and demand, and the relationship between each company and its national political context is summarised in the concluding section.

\section{Social demand for environmental and climate change protection}

Social demand for environmental protection affects corporations engaged in activities associated with environmental risk. Organised social interests can influence consumer behaviour and thus be an important determinant for corporate choice by creating pressure and opportunities. Companies guard their reputations and public images mainly for economic reasons. Boycotts of Shell's petrol stations in Germany linked to the Brent Spar incident showed that losses from the boycott could cost more than the dumping alternative (Estrada et al., 1997). ExxonMobil has been concerned for its brand name as a result of the consumer boycott initiated by the green movement over Exxon's climate strategy. ${ }^{1}$ Globalisation of communication exposes company incidents from all corners of the world. Shell's experience in Nigeria in the mid-1990s illustrates that there is nowhere to hide from negative media attention and loss of international reputation. Conversely, a high social demand for climate policy can provide market opportunities for companies by increasing 'green' consumers' willingness to pay a higher price for clean energy products. The largest Nordic energy company - the Swedish Vattenfall AB - has, for example, exploited new market opportunities by a variety of means and gained commercially from 
consumers' willingness to pay an extra price for clean energy (Eikeland, forthcoming). As argued in chapter 2, there is reason to assume that social demand affects corporate climate strategies differently depending on the companies' national ties. This is particularly true whenever national imprints overlap with market exposure.

ExxonMobil, Shell and Statoil are most directly exposed to the general public and green organisations through their petroleum product sales: in most parts of the world, consumers can choose between retail stations owned by Shell or ExxonMobil. As noted in chapter 4, the US retail market is most important to ExxonMobil. In contrast, the European market is most important to Shell, while Statoil has divided its activities between Norwegian and 'international'. In 1999, Statoil controlled 26 per cent of the market share for petrol sales in Norway, and most of its total refining capacity is located there. ${ }^{2}$

Against this backdrop, we assume that ExxonMobil is most exposed to a social demand for environmental protection in the US, Shell in the Netherlands and Europe, and Statoil in Norway. Based on the companies' climate strategies, we would expect that social demand - in relative terms - ranks highest in the Netherlands and Europe, lowest in the US and somewhere in between in Norway.

Several public opinion surveys have included questions about threats to the environment and attitudes to environmental protection since the 1970s. However, cross-country comparability and consistency of longitudinal data-series vary because of differences in the way questions are worded as well as in the context in which they are asked. To increase validity, we will use surveys that ask several different questions about the same phenomenon, and support public opinion surveys with interviews focusing on how social demand is actually perceived by corporate decision-makers. The organised green movement, 'green' political parties and other political parties will also be included, since they are important actors in translating public support for environmental protection into political power and climate policy. As noted in chapter 2, social demand can affect corporate strategies indirectly as well as through public policy. 
The Netherlands: high social demand

With Shell's recent reorganisation, it is firmly connected with a home-base country from which corporate strategies on issues such as climate change are developed. Shell is a European company closely linked to the Netherlands. Two faces of the company appear there: Shell Netherlands BV and Shell International. Shell Netherlands possesses refineries and gas stations, and constitutes a relatively large part of the Shell Group of companies. For example, Shell's refining capacity in the Netherlands is more than twice as high as in the US. In climate policy, the main task of Shell Netherlands is to influence and implement the climate strategy of Shell International, which has the main responsibility for developing the overall climate policy for the Shell Group of companies worldwide. Shell International is located in the UK, but is heavily influenced by Dutch culture, society and policy. This influence is effectively channelled through ownership (the Shell group is 60 per cent Dutch owned), and representation on the boards of management and in the climate unit in Shell International. As pointed out by one observer, 'Shell has its backbone in the Netherlands.' ${ }^{3}$ Moreover, national imprints overlap with market exposure in the Netherlands and Europe in terms of risks and opportunities.

A number of studies have shown that Europeans in general have been significantly more receptive to proactive policies on climate change - among both the 'elite' and the 'general public' than have North Americans. ${ }^{4}$ And the Netherlands is widely perceived as being among the 'greenest' countries in the world. Involvement in environmental issues, the attention paid to environmental problems, and environmentally friendly behaviour have been systematically monitored in the Netherlands since the 1980s (Bartels, 1995). ${ }^{5}$ Up to the mid-1990s the environment was regarded as the most important social problem. From around 1994 there was a slight downward trend, when the environment shared its leading position with other issues such as crime and unemployment.

Dutch citizens are apparently willing to pay an extra price for clean energy to help combat climate change (Werf, 2000). In 1995, 60 per cent of the population in the Netherlands stated their willingness to pay higher prices for environmentally friendly products. Over 40 per cent of the population was willing to pay 
higher taxes for better environmental quality and was even willing to accept a lower standard of living. ${ }^{6}$ Involvement of citizens in the climate-change issue has varied according to publicity for specific events (Schenkel, 1998). ${ }^{7}$ A peak occurred in 1992 related to the Rio conference (almost 40 per cent involved). The corresponding figure in 1996 was slightly above 30 per cent (VROM, 1997).

The relatively high social demand has led Shell to use the Netherlands as a test ground for society's willingness to pay for environmental protection in general, and clean energy in particular. ${ }^{8}$ In essence, the Netherlands serves as a sort of playground for Shell's investment in renewable technology. Inglehart (1971) has proposed that the environmental movement represents a political expression of post-materialistic values that will be strengthened as the new generations become older. Weale (1992: 138) claims that a high proportion of the population in the Netherlands is influenced by post-materialistic values, in Inglehart's terminology. This underlying trend contributes to making the Netherlands an interesting test case for future demands for clean energy.

Time-series data on membership and income patterns among the most important Dutch ENGOs show a steady increase up to the mid-1990s (Skjærseth, 1999). This peak corresponds with Shell's process of reorganisation initiated in the mid-1990s. The Dutch green parties have had a relatively stable and high electoral basis since 1984. In 1989, the Green Left won six parliamentary seats out of 150 and doubled the number of seats of the constituent parties. The 1994 election left them with five seats. In 1998, political parties with green ties increased their share of seats in parliament, thus indicating that the decline in Dutch awareness has been modest. For example, the Green Left more than doubled its share of seats in parliament to 11 (Luciarde, 1999). The sensitivity of other political parties partly explains why the Dutch greens have not had even stronger support. Public perception of environmental issues has little to do with voting behaviour in the Netherlands (Tak, 1994: 11). An analysis of the parties' programmes shows that all major political parties have adopted green ideas, and do not differ significantly in their rhetorical support for environmental protection.

The development in Dutch social demand for environmental and climate policy appears in line with expectations. The climate 
strategy of Shell accords well with social demand in the Netherlands. Moreover, Europeans have generally been more receptive than the US to an active climate policy. The Dutch home-country context of Shell constitutes a population where a large share of the consumers have signalled their willingness to pay higher prices for environment-friendly products and clean energy. This has led Shell to use the Netherlands as a test country for predicting future social demand. Conversely, Shell's petroleum product sales in Europe make the company vulnerable to negative attention and consumer campaigns.

\section{The United States: low social demand}

ExxonMobil is deeply rooted in the US even though the company operates all over the world. Exxon Corporation started out as Standard Oil in 1882, and the corporation's headquarters is located in Irving, Texas, where corporate staff develops Exxon's environmental strategy. Exxon's US cultural heritage has been seen as important for the company's choice of environmental strategy (Estrada et al., 1997). Like the case for Shell, national imprints overlap with ExxonMobil's market exposure in the US.

North Americans express significant concern for the environment, but climate change is given little public attention compared to other environmental problems.

Table 5.1 Percentage expressing 'a great deal' of concern in the US

\begin{tabular}{lcccc}
\hline Issue & & & & $\begin{array}{c}\text { Change } \\
\text { since 1989 }\end{array}$ \\
\hline Pollution of drinking water & - & 68 & 72 & - \\
Pollution of rivers, lakes and & & & & \\
$\quad$ reservoirs & 72 & 61 & 66 & -6 \\
Contamination by toxic wastes & 69 & 63 & 64 & -5 \\
Ocean and beach pollution & 60 & 50 & 54 & -6 \\
Air pollution & 63 & 52 & 59 & -4 \\
Contamination by radioactivity & 54 & 48 & 52 & -2 \\
Loss of habitat for wildlife & 58 & 51 & 51 & -7 \\
Damage to the ozone layer & 51 & 44 & 49 & -2 \\
Loss of tropical rain forest & 42 & 49 & 51 & +9 \\
Global warming & 35 & 34 & 40 & $\mathbf{+ 5}$ \\
Acid rain & 41 & 29 & 34 & -7 \\
\hline
\end{tabular}

Source: Based on Saad and Dunlap (2000). 
Data displayed in table 5.1 are not directly comparable with Dutch data. This means that the percentage expressing 'a great deal' of concern in the US cannot be directly compared to the Dutch measure of 'involvement'. However, table 5.1 provides information on trends and the rating of climate change as an issue within the US. First, of the eleven issues included here for which longitudinal data exist, public concern has been reduced for eight. We should bear in mind, however, that public concern for the environment ranked particularly high in 1989 owing to, among other things, a high level of media attention linked to the March 1989 Exxon Valdez oil spill - the largest in US history (see chapter 4). This Exxon-caused incident contributed to raising the social demand for environmental protection in the US (Saad and Dunlap, 2000). Second, there have been significant fluctuations the last decade. This indicates a pattern in line with 'issue-attention' cycles (Downs, 1972), which provide companies with an ambiguous social context. Thirdly, global warming is located at the bottom of the spectrum in spite of an increased concern between 1999 and 2000. A study of media coverage of climate change follows roughly the same pattern and shows significant fluctuations with a peak in 1997, when the Kyoto Protocol was signed (Agrawala and Andresen, 1999). ${ }^{9}$

The US public worries about national environmental issues such as water and air pollution as well as toxic waste, rather than international ones such as climate change (OECD, 1996). A Gallup poll released in connection with the Kyoto negotiations indicates that North Americans are somewhat inconsistent in their attitudes to climate change (Gallup and Saad, 1997). On the one hand, a majority believes that the problem will have harmful effects within the next 25 years. On the other hand, they are not willing to accept significant costs or a large share of the international burden to reduce the problem. This indicates a different attitude among US consumers and those in the Netherlands. While Shell perceives the Dutch consumers' willingness to pay for clean energy as a business opportunity, fossil-fuel interests in the US have launched PR campaigns to highlight the high economic costs for consumers resulting from GHG emissions reductions. For example, Exxon Education Foundation's Exxon Energy Cube, with videos, books, games and posters, 'implies that fossil fuels in general pose few environmental problems and that alter- 
native energy is unattainable and costly' (Levy and Egan, 1998: $350)$.

According to Skolnikoff (1997), the role of public opinion in the US is unclear because climate change is not a major issue on the public agenda. Social 'demand' for a stringent climate policy generated from 'below' appears to be a misleading description of the US situation. The Clinton administration did in fact make an effort to create such a demand through various education campaigns. A number of governmental initiatives under the heading 'public outreach' were launched in the 1990s aimed at increasing public awareness by a number of means, from multimedia presentations to displays in shopping malls (DSP, 1997).

With a low public demand for climate policy and a low willingness to pay for clean energy, ExxonMobil has not had strong incentives to exploit market opportunities related to renewables in the US. Instead, the company has sought to keep demand for stricter climate policy low through PR campaigns. According to the company, oil and gas are significantly more profitable than renewables. ${ }^{10}$ ExxonMobil also maintains that the company has poor experience with renewables: in the 1970s, Exxon, like many other companies such as Shell, invested unsuccessfully in renewables like solar energy.

US ENGOs reflect the difference in attention between domestic and international environmental problems. On the one hand, green groups are a vital force in American society with respect to domestic problems: 16 per cent of Americans say they are active in the environmental movement, while 5 per cent indicate a membership in large national and international organisations such as the Sierra Club and Greenpeace. Compared to other social groups, 43 per cent strongly agree with the goals of the environmental movement, which places it as number three of eight major social movements after the civil and women's rights movements. In terms of perceived impact on policy-making, however, green groups clearly lag behind two additional movements: gun control and abortion rights (Dunlap, 2000).

On the other hand, while climate change has top priority in Greenpeace International based in Amsterdam, Greenpeace-US in Washington, DC, finds it difficult to raise funding for campaigns for the Kyoto Protocol, owing to low public concern. Even though US ratification of the Kyoto Protocol, would have been 
the key to a viable climate regime, Greenpeace-US resigned from its efforts to lobby for US ratification even before George W. Bush was elected president in the autumn of $2000 .{ }^{11}$ It is quite illustrative that the Stop Esso campaign specifically targeting ExxonMobil's climate strategy was initiated in Europe and not in the US (see chapter 4). In July 2002, a Greenpeace-commissioned survey, undertaken by the polling agency MORI, showed that a significant number of British motorists have stopped buying petrol from Esso stations and have switched to other retailers as a result of the Stop Esso campaign. Esso, however, denies the result and says that the company's business has not been affected. ${ }^{12}$ In essence, the green groups are able to exploit a higher level of political concern in Europe that may affect the market shares of ExxonMobil.

The US party system is significantly different from those of most European states, including Norway and the Netherlands, owing to the dominance of two parties and the lack of proportional representation. Crudely put, the environment is typically a liberal concern in the US, and thus advocated by the Democrats. Republicans frequently oppose environmental legislation since an active environmental policy is perceived to hamper economic growth, raise unemployment and cause more government. The two-party 'winner-takes-all' system prevents environmental issues from becoming major political issues in the US. Environmental issues have seldom been a major factor in national elections in the US: environmental protection was ranked as issue number eight in a recent Gallup poll (Saad and Dunlap, 2000). Norway and the Netherlands have both experienced the resignation of governments triggered by a climate-related issue - events unlikely to take place in the US (see below).

Social demand for climate policy in the US appears somewhat ambiguous, but corresponds roughly with expectations. On the one hand, a large proportion of the US public expresses concern for the environment, and ENGOs are a vital force in US society. On the other hand, the US public worries mainly about national environmental issues and does not accept significant costs to deal with climate change. In addition, environmental protection, including climate change, ranks low on the political agenda. The social pressure exerted on ExxonMobil concerning climate change thus appears relatively low. International ENGOs such as 
Greenpeace gear their resources towards the European face of ExxonMobil: Esso. Equally important is the North Americans' unwillingness to pay a higher price for clean energy. The fossilfuel lobby has exploited these attitudes, and ExxonMobil does not perceive investments in renewable energy sources as an interesting business opportunity.

\section{Norway: fluctuating demand}

Statoil has concentrated most of its operations on the Norwegian continental shelf, and it plays a crucial role in the Norwegian economy: in 1998, the Norwegian petroleum sector accounted for 11.8 per cent of GDP and 29.8 per cent of total export (Andersen and Austvik, 2000). Statoil is a significant supplier of natural gas to Europe and the largest retailer of petroleum products in Scandinavia. Statoil's headquarters are located in Stavanger, Norway. The link between Norway and Statoil is thus very strong and direct: 'Statoil's own trademark is to a large extent Norway's trademark' (Estrada et al., 1997: 149). The overlap between national imprints and market exposure is thus extremely strong in the case of Statoil.

Norwegian attitudes to climate policy and the environment have fluctuated significantly over time. Surveys on the importance of environment and energy issues conducted as part of national election research show quite dramatic variation. ${ }^{13}$ In 1989 , the environment and energy ranked as the second most important political issue overall, and 37 per cent considered it the most important. By 1993, the environment and energy issue had dropped to number five, and it was considered most important by only 7 per cent (Aardal and Valen, 1995). The significant increase in interest in the latter part of the 1980s and the decline in 1993 are also confirmed by a number of other surveys (Skjærseth, 1999). Furthermore, the level of public concern witnessed from 1993 seems to have stabilised at a low level. For example, in 1990, 23.5 per cent thought that public expenditures on the environment should be increased significantly, while the corresponding figure in 1996 was 8.8 per cent (Skjåk and Bøyum, 1996).

Less concern for environmental problems has also been revealed by a study called Norsk Monitor. ${ }^{14}$ In 1989, 61 per cent characterised the situation as 'grave' and agreed with the need for 'drastic action'. The corresponding figures in 1997 and 1999 were 
34 per cent and 28 per cent respectively. Of five environmental problems, global warming is ranked after ozone depletion and acid rain in the same study. However, the population's fear of climate change has decreased significantly: in 1989,40 per cent of the population was very worried, while only 22 per cent was worried in 1997. In short, Norwegian developments seem largely in line with the patterns following from Downs' (1972) idea of issue-attention cycles. Statoil has been exposed to more ambiguous demand than Shell in the Netherlands. Moreover, Norway relies heavily on renewable hydroelectric power at the outset and electricity prices have been low. This makes the market for solar, wind, wave or biomass very small and efforts to introduce 'green' electricity almost futile. Statoil does not see any great market opportunities for these energy carriers. In January 2000, Statoil withdrew from a joint venture on wind power, arguing that it could not see any future profitability for wind power in Norway. ${ }^{15}$

The largest ENGO in Norway, Naturvernforbundet (Society for the Conservation of Nature), decreased significantly in both membership and income between 1993 and 1995 . Naturvernforbund has since remained small in comparison to the beginning of the 1990s. The growth and decline of the organisation illustrate a general trend in membership among the most important Norwegian ENGOs (Jansen and Osland, 1996). Statoil has generally been influenced by Norwegian ENGOs, but the company has not been exposed to any serious threats of boycotts over its climate policy from the green movement in Norway. However, ExxonMobil has been targeted in Norway as part of the Stop Esso campaign. ${ }^{16}$

There is no truly 'green' party in Norway. This phenomenon has been explained by the general sensitivity of the political system to new social demands. Existing political parties have largely managed to absorb a potential 'green' party electorate. As in the Netherlands, few voters perceive environmental issues as important for party choice, except for two small parties - the Socialist Left and the Liberal Party. These have to some extent filled the niche for a 'green' party (Seippel and Lafferty, 1996).

Public opinion data in Norway are not directly comparable with either Dutch or US data. However, we have a strong impression that Norwegian demands have been the least stable during 
the 1990s. There has been some social pressure mediated by ENGOs on Statoil's climate policy, but market opportunities for new renewable energy have been perceived as minor. Solely on the basis of social demand, we would expect the climate strategy of Statoil to be more in line with ExxonMobil's than Shell's.

\section{Comparison of social demand}

Even though comparison of social demand across countries is difficult, because different questions are asked in different contexts, we can draw some conclusions about relative trends and differences. First, a dividing line seems to go between the US and Europe: public opinion, green organisations and political parties exert a stronger pressure for climate change measures in Europe than they do in the US. The most visible expression of this phenomenon is perhaps the resignation of governments over climate-related issues in both the Netherlands and Norway - incidents that are unlikely to occur in the US. Second, there are significant differences within Europe, as reflected in those between Norway and the Netherlands. Social demand for climate policy appears to be higher and more stable in the Netherlands than in Norway. This means that all three cases roughly support our expectation of a close link between social demand in their homebase countries and corporate climate strategies: the home-base country context of public pressure and opportunities varies in accordance with the climate strategies of Shell, ExxonMobil and Statoil.

However, causal relationships between social demand and corporate climate strategy are more difficult to establish than the correlations witnessed above. Shell uses the Netherlands as a test country for the future of opportunities for clean energy. Thus, social demand in the Netherlands and Europe seems to be one important explanatory factor for Shell's proactive climate strategy. In the case of Statoil, the extreme importance of Norway and Norwegian markets has apparently led the company to follow fluctuations in public opinion. Lack of viable market opportunities for renewable energy other than hydroelectric power, combined with only moderate social pressure, can shed some light on Statoil's climate strategy. ExxonMobil has been described as a super-tanker: steady and strong. Currently, pressures and opportunities signalled from US society do not provide ExxonMobil 
with sufficient incentives to change course. However, the European market is also important to ExxonMobil, and the company has recently been exposed to substantial campaigns in Europe explicitly linked to its climate strategy. ExxonMobil appears less vulnerable to European pressures than Shell - at least for the time being.

All in all, we can conclude that social demand in the companies' home-base countries corresponds with expectations derived from the DP model. However, social demand represents only a part of the total causal picture. In the next section, we will look at the supply side, i.e. the link between governmental climate policy and corporate climate strategies. To various degrees, climate policy is likely to reflect social demand in democratic societies. Social demand can thus also affect corporate strategy indirectly through public policy. However, this link also depends on the respective political institutions' sensitivity to new social demands. While environmental concerns have been quickly absorbed into the multi-party political systems of Norway and the Netherlands, these issues apparently have more difficulties in penetrating the US two-party system.

\section{Governmental supply of climate policy}

This section aims to explain differences in corporate strategies from the perspective of governmental supply of climate policy. The main focus is on how national climate policy affects the oil industry rather than why the policy itself changes and varies. ${ }^{17}$ Corporate response is likely to depend on the level of ambition of the climate policy measured in terms of targets and policy instruments. A viable climate policy creates regulatory pressure, grants market opportunities and reduces uncertainty for companies with regard to future governmental priorities.

Ambitious GHG reduction targets linked to mandatory policy instruments send a clear signal to industry. In such situations, governments show that the problem is taken seriously and action is expected at the level of target groups. Company response can thus reflect a desire to avoid further costs of governmental regulation. If these targets are combined with an ambitious governmental policy on renewable energy, stimulating market opportunities, companies can be expected to respond proactively. 
Conversely, a situation characterised by lenient GHG targets, voluntary public programmes and low priority for renewables is likely to spur a reactive response whenever the climate issue is perceived as a potential threat to business interests. A combination of high social demand and an ambitious climate policy will create a positive interplay between factors pulling in the direction of proactive climate strategies.

Against the backdrop of the corporate climate strategies observed in chapter 3, we assume that the Netherlands has adopted the most ambitious climate policy, followed by Norway and the US - in that order. The term 'ambitious' should be understood in relative terms only, not according to the actual requirements of the problem at hand.

In the following section, we have distinguished between overall climate policy and targets, and policy instruments directly affecting the oil industry.

\section{The US: low ambition}

Overall climate policy The US is the single largest contributor to global GHG emissions (about 25 per cent of the global total). Accordingly, domestic US efforts to combat climate change would make a significant difference in terms of global anthropogenic emissions. A Kyoto agreement without the United States was until the 2001 Bonn Summit widely perceived merely as a theoretical possibility. ${ }^{18}$ This means that US climate policy during the $1990 \mathrm{~s}$ sent an extremely important signal about the road ahead to the US oil industry and ExxonMobil.

US climate policy can be divided into three phases, corresponding roughly with changes in administrations and international developments. The first phase covers the period up to the 1992 Rio Summit and the last year of the Bush-Quayle administration. The second commences with the Clinton-Gore administration in 1993 and ends before the run-up to the Kyoto conference in 1997. The third runs from the Kyoto negotiations to the Bush-Cheney administration.

Spurred by the drought and heat waves that hit the US in 1987 and 1988, the Bush-Quayle administration initially expressed deep concern about threats to the global climate. However, initial enthusiasm rapidly declined, and the administration became 
critical of the findings of the IPCC's first assessment report (Bergesen et al., 1995). As this was combined with fear of large socio-economic costs that could threaten 'the American way of life', the US was reluctant to support an international agreement including 'targets and timetables' during the negotiations for a climate convention in the Intergovernmental Negotiating Committee (INC) that commenced in $1991 .{ }^{19}$ The US preferred a comprehensive and flexible approach - one that would include the sources and sinks of all GHGs within the framework of any climate agreement (Agrawala and Andresen, 1999). ${ }^{20}$ This position is usually referred to as the 'bottom-up' approach, emphasising action from below, in contrast to the 'top-down' targets-andtimetables approach preferred by most European states. ${ }^{21}$ Having succeeded in keeping targets and timetables out of the UNFCCC, the US, as one of the first countries, both signed and ratified the convention in 1992. This indicates a close match between national interests and the final international output.

The Clinton-Gore administration took office in January 1993 and initiated the second phase of US climate policy. This is characterised, first, by the adoption of a unilateral target. In April 1993, Clinton announced that the US had committed itself to reducing emissions of greenhouse gases to their 1990 levels by the year 2000. The Clinton-Gore administration also presented an action plan on how to reach the stabilisation target. A British thermal unit (BTU) tax was initially proposed based on the heat content of the fuel. This tax aimed to stimulate energy efficiency and cut federal deficit by raising about US\$72 billion in tax revenues over five years. The tax was, however, turned down by the Senate in spite of a Democratic majority in Congress. The energy tax provoked the US oil industry, which played a crucial role in killing it.

Shortly after the tax defeat, the Clinton administration announced the 1993 Climate Change Action Plan (CCAP), which aimed to increase energy efficiency in various sectors. In 1997, the US followed up the CCAP with the United States Climate Action Report (USCAR) to the UNFCCC. These plans aimed at tapping the large potential for reducing GHGs in the US by means of 'no regrets' measures.

CCAP and USCAR consist of more than 40 actions that are to be implemented primarily by public voluntary programmes, 
information campaigns and partnerships between business and government. More than 5,000 organisations from around the country participate in CCAP/USCAR programmes. Most of these programmes represent 'no regrets' measures that focus on technological innovation and use. The programmes seek to create markets for investments in existing, or close to existing, technologies capable of reducing emissions. Thus, the principal task of the government was to stimulate innovation through voluntary programmes and correct market failures by means of information and persuasion.

There has been a heated debate between different departments and agencies on the effectiveness of the climate change programmes (OECD, 1999). However, the CCAP did not achieve, or even come close to achieving, the stabilisation target. Between 1990 and 2000, US GHG emissions increased by 14.5 per cent (EPA, 2002). In fact, the stabilisation target was never taken seriously by the US oil industry. First, the plans significantly underestimated the reductions needed to return emissions to 1990 levels by the year 2000. Second, the plans were not fully funded. Republicans had a majority in Congress from 1995 and generally resisted new taxes or increased spending. ${ }^{22}$ Third, the plans had very low political priority. The priority of the US during the 1990s was research, not action (Brunner and Klein, 1998).

The Clinton-Gore administration supported the second IPCC assessment report. Since the late 1950s, US federally supported science has been the single most important cause in identifying climate change as a global problem. The US led the establishment of the IPCC, which provided the scientific background in the form of assessment reports upon which both the UNFCCC and the Kyoto Protocol rest (see chapter 6). However, US scientists remain split on this issue and some even deny the validity of the IPCC analysis altogether. This is particularly important for US positions and policy, since the US tradition allows more scientific involvement in policy matters than is the case in Europe (Skolnikoff, 1997).

After 1995, the Republicans controlled both the Senate and the House of Representatives in Congress. Nevertheless, the US government agreed to, and signed, the 1997 Kyoto Protocol, which calls upon the US to reduce GHG emissions by 7 per cent from 1990 levels. While the US fossil-fuel industry, with Exxon as 
one of the most prominent leaders, to a large extent controlled the development of national US climate policy, this move by the Clinton-Gore administration indicates that the international process developed beyond the control of ExxonMobil. The US Kyoto commitment implied a dramatic strengthening of US climate policy. Analysis showed that the US would have to reduce emissions by the order of 30 per cent relative to a 'business as usual' scenario to reach the Kyoto target. ${ }^{23}$ However, the Senate would have to ratify the Kyoto Protocol before it could be viewed as a part of US policy (see chapter 6).

Four years later, in January 2001, the former Texas governor George W. Bush was elected president. In March 2001, Bush Jr declared that the Kyoto Protocol was unacceptable because it would harm the US economy and because it failed to hold developing countries to strict emission limits. In February 2002, Bush unveiled proposals for a voluntary scheme to curb GHG emissions. ${ }^{24}$ This represented a continuation of the voluntary approach under the Clinton-Gore administration, bringing US climate policy back to square one. In retrospect, US climate policy may over time be characterised as relatively weak. This pattern was, however, severely disrupted by the US Kyoto commitments lasting from 1997 to 2001.

Policy instruments and the oil industry The 1993 CCAP and 1997 USCAR do not include programmes directly targeting the oil industry, but comprise general cross-sector programmes that affect this industry together with others. 'Green Lights and Energy Star', 'Climate Wise' and 'Climate Challenge' are among the most important programmes. ${ }^{25}$ For example, 'Climate Wise' focuses on the industrial sector, which accounts for about 30 per cent of US energy consumption. The programme helps companies realise their energy efficiency potential by providing technical assistance and public recognition. Each participating company is to develop an action plan within six months and report results of its actions annually.

Company members of the API participate in various voluntary programmes including 'Climate Wise', 'Green Lights' and 'Natural Gas Star'. ExxonMobil has generally shown little interest in the programmes, arguing that none of them has led the company to take action that departs from what it would have 
done in their absence. ${ }^{26}$ However, ExxonMobil and Shell participate in the 'Natural Gas Star' programme. According to the Environmental Protection Agency (EPA), this programme has been an outright success. By the year 2010, it aims at energy cost savings in the order of US\$100 million and methane savings of 55 billion cubic feet. ${ }^{27}$ As of spring 1999, the programme included 17 production partners and 53 transmission and distribution partners. The partners have exceeded CCAP goals by preventing the release of 75.8 billion cubic feet of methane gas, valued at about US\$152 million. The producers have accounted for 51 billion cubic feet. ${ }^{28}$

The US oil industry is also heavily subsidised. For national, economic and energy security reasons, the government is strongly involved in this sector. The defence of Persian Gulf oil supplies and the commitment to maintain a government-owned strategic petroleum reserve constitute two important (energy) policy goals. The introduction of additional supplies into the market is seen as an effective way to dampen the price rise and mitigate the economic damage resulting from severe oil supply disruption. These and other subsidies are provided to producers, transporters and consumers. According to Greenpeace, subsidies in domestic oil are worth between US\$1.20 and US $\$ 2.80$ per barrel of domestic crude consumed. Cutting subsidies would thus represent an effective climate-change strategy (Koplow and Martin, 1999).

In sum, ExxonMobil was during the 1990s exposed to weak and ambiguous climate-policy targets in the US. ExxonMobil did not take the US stabilisation target seriously, but the US Kyoto commitments represented a temporary change in ambitions. At the policy instrument level, ExxonMobil has voluntarily participated in public programmes, though without much enthusiasm. In short, ExxonMobil has been exposed to a national climate policy context characterised by high political uncertainty and little regulatory pressure.

\section{The Netherlands: High ambition}

Overall climate policy Because of a concern for sea-level rise, the Netherlands was perhaps the only OECD country that responded ambitiously to climate change throughout the $1990 \mathrm{~s}$ (VROM, 1999). ${ }^{29}$ For Shell, the Netherlands not only constitutes 
a 'test country' for pressures and opportunities offered by the general public but also represents a test case for what the industry can expect from a relatively viable climate policy.

In November 1989, the Dutch government announced its decision to stabilise $\mathrm{CO}_{2}$ emissions at the 1989/1990 level by 1995 at the latest. In 1990, a revised plan called for a 3-5 per cent reduction from average $1989 / 1990$ levels by 2000 . In 1995 , the $\mathrm{CO}_{2}$ target was reformulated to a 3 per cent reduction from the 1990 level by 2000. In 2002, the Netherlands was the first of the EU member states to ratify the Kyoto Protocol. Simultaneously, policy instruments have been gradually stepped up. This has primarily taken place in the various National Environmental Policy Plans (NEPPs), as well as in a number of white papers covering other sectors of society such as energy, transport, agriculture and waste (VROM, 1989, 1993, 1998). The Netherlands is renowned for its comprehensive environmental planning, and climate policy is no exemption: between 1993 and 1997 the Dutch authorities published about 30 policy documents with relevance for climate change (VROM, 1997). In 1999, three new packages of policy instruments and measures were proposed (VROM, 1999). In spite of these efforts, $\mathrm{CO}_{2}$ emissions grew by about 11 per cent between 1990 and 1997 due to lower energy prices and higher economic growth than expected.

There are no distinctive phases in Dutch climate policy. At the domestic level, the Netherlands has gradually stepped up its efforts over time. The Dutch position has traditionally been that domestic reductions are most important, and the main reduction of GHGs should come from the industrialised countries (IEA, 1994). The Netherlands has therefore been in a good position to be in the forefront at the EU and the global levels.

Climate change was first mentioned domestically at the beginning of the 1980s. The need to offset the expected sea-level rise was placed on the agenda by a report published by the Public Health Council in 1986 - the year that experts started to prepare the report Concern for Tomorrow. ${ }^{30}$ This report was released in 1988 and alerted the general public and politicians alike by painting a dark picture of the state of the Dutch environment. Because of its scientific credibility, the report had a profound impact (Bennett, 1991). Moreover, the rising tide of public opinion affected the political climate (Weale, 1992). In the 1989 election, 
the environment in general and climate change in particular became prime issues. The first NEPP was released in 1989. NEPP 1 shifted the focus from regulations and standards to negotiated agreements between the government and sector target groups. In the field of climate change, the target was set to stabilisation of $\mathrm{CO}_{2}$ emissions by 1995 at their 1989/1990 level. The main policy instrument to achieve this goal was negotiated agreements with specific industrial target groups and other sectors.

NEPP 1 is probably best known for triggering the fall of the first Dutch cabinet on the grounds of an environmental issue. The Christian Democratic/Liberal coalition had to resign in 1989 because the Liberals resisted raising the costs of car driving. The new government - a coalition of Christian Democrats and the Labour Party - published a new version of NEPP in 1990: NEPP Plus. NEPP Plus went further than NEPP 1 by adopting the 3-5 per cent reduction target to be achieved by 2000 (VROM, 1991).

NEPP 2 was released in 1993 and signalled that the objectives of NEPP Plus would continue to apply (VROM, 1993). NEPP 2 placed more emphasis on strengthening implementation, particularly with regard to 'diffuse' sources, and target groups that were difficult to reach by means of negotiated agreements. An energy tax was proposed to reach such groups. The government preferred to work vigorously for an EU-wide tax, but was prepared to adopt a national tax if the EU tax did not materialise. A regulatory energy tax for small consumers was adopted in 1996. The green tax is regulatory since it aims explicitly at reducing consumption. It applies to natural gas and electricity consumption and comes in addition to the environmental tax on all fossil fuels. ${ }^{31}$ The tax raises energy prices for small-scale consumption by $15-20$ per cent. Renewable energy is exempt from the tax. The small-consumer tax is expect to contribute to a total $\mathrm{CO}_{2}$ emissions reduction of the order of $1.5-5$ per cent (Baron, 1996).

In the 1995 third White Paper on energy, the aim was to increase the share of renewable energy to 10 per cent of total energy consumption and to improve energy efficiency by onethird in the year 2020 compared to 1990. The current share of renewables in the Netherlands was about 1.5 per cent. Over the preceding few years, policies to promote renewables had been 
strengthened by the introduction of a wide range of fiscal arrangements, such as energy investment tax credits. Renewable energy was also promoted through its inclusion in the long-term agreements (VROM, 1999). The 1995 and 1996 goals on renewables directly influenced Shell's decision to establish Shell International Renewables in $1997 .{ }^{32}$

The third NEPP issued in 1998 followed the same path as NEPP 2 (VROM, 1998). The main message was to strengthen policy instruments and measures in order to reach the targets adopted in NEPP Plus. With respect to climate change, the Cabinet intended to increase energy taxes except for heavy energy consumers. In 1999, the Ministry of Housing, Spatial Planning and the Environment (VROM) presented a new climate policy implementation plan (VROM, 1999). The plan was developed in response to scenarios showing that GHG emissions, particularly of $\mathrm{CO}_{2}$, would continue to grow under current policies. The new plan was based on a package approach. The Netherlands assumed that about half of the cutbacks could be dealt with through the flexibility mechanisms in the Kyoto Protocol. The basic package consisted of measures and instruments expected to bring about the necessary reductions, excluding the share under the flexibility mechanisms. Increasing the share of renewable energy, further improvement of energy efficiency, and measures taken at coalfired power plants were the main strategies for the future. The reserve package was designed to reduce emissions quickly if the basic package failed. The core of this package consisted of raising the regulatory energy tax and excise duties on motor fuels, reducing $\mathrm{N}_{2} \mathrm{O}$ from emissions in the chemical industry and storing $\mathrm{CO}_{2}$ underground. Implementation of this package required future political decisions. In addition, an innovation package was prepared primarily for continuous reduction beyond the Kyoto horizon. This package aimed to promote innovation in technology and in governmental policy instruments that might stimulate GHG reductions.

The EU member states and the Commission have tried to hammer out some sort of burden sharing within the EU since the EU adopted its stabilisation target in 1990. Particularly, Greece, Ireland, Portugal and Spain feared that EU climate policy could hamper their economic development. Earlier efforts were, however, unsuccessful until the Netherlands assumed the 
EU half-year rotating presidency in January 1997. The internal EU negotiations were part of the global negotiation process - in which the EU had strong leadership ambitions. The Netherlands played an important role in this process by proposing the 'Triptique Approach' (Ringius, 1997). ${ }^{33}$ In contrast to the previous targets- and-measures view, this new approach paved the way for a binding EU agreement finalised in June 1998. The EU proposed, first, that the OECD countries should cut their GHG emissions by 15 per cent in 2010. Second, the Council set forth a burden- sharing agreement including emissions targets for each member state. While some states were allowed to increase their emissions, the Netherlands was required to reduce its by 10 per cent in 2010 relative to 1990 levels. ${ }^{34}$ In short, the Netherlands sent a clear message to industry that contains both pressures and opportunities.

Policy instruments and the oil industry The Dutch oil industry is beginning to accept the reality of climate change and to consider measures in response. Dutch and EU initiatives on renewable energy have had a significant impact on Shell's climate strategy. The company believes that renewables will become the main energy source in the future and perceives them as an interesting business opportunity (see chapter 3). Accordingly, Shell seeks to create a new image as an energy company with increasing activities in solar power and biomass.

However, the main policy instrument applying specifically to the oil and gas production sector is a long-term agreement (LTA) that was concluded between the authorities and 12 companies and ventures in 1996. One of these is Nederlandse Aardolie Maatschappij BV, which is a 50-50 joint venture between Dutch Shell and Exxon. This agreement sets the target for energy efficiency improvement over the period 1989-2000 to 20 per cent. The measures needed to achieve this objective are set out in a long-term plan for improvement of energy efficiency. This is confidential, but all such plans include the following elements (Nuijen, 1999):

- an assessment of energy consumption in the reference year 1989;

- a survey of opportunities for energy efficiency improvement; 
- a model for company energy plans;

- monitoring and energy management in each company;

- research and development on new low-energy technologies;

- demonstration projects for energy-saving measures;

- market introduction of low-energy techniques;

- assistance to individual companies;

- transfer of know-how and information.

The oil and gas production sector has improved energy efficiency in the field of transport, oil pumps and processes. Nearly half the improvements stem from process modification in order to recover cooling water (Novem, 1999).

Negotiation of an LTA typically takes from one to two years, from a letter of intent to signature. The impact of the LTA is very hard to assess, but table 5.2 indicates that a large part of the improvement would have taken place in any case: before 1996, 18 per cent had already been achieved in the absence of the LTA. On the other hand, the largest share of improvement in energy efficiency occurred after the signing of the agreement.

Table 5.2 Improvement of energy efficiency in Dutch oil and gas production

\begin{tabular}{ccc}
\hline Year & $\begin{array}{c}\text { Energy efficiency } \\
\text { index }{ }^{a}\end{array}$ & $\begin{array}{c}\text { Energy efficiency improvement in } \\
\text { TJ/year }\end{array}$ \\
\hline 1989 & 100 & 0 \\
1990 & 99 & 347 \\
1991 & 98 & 359 \\
1992 & 94 & 947 \\
1993 & 92 & 1181 \\
1994 & 86 & 2419 \\
1995 & 82 & 1749 \\
1996 & 80 & 1178 \\
1997 & 75 & 3710 \\
1998 & 70 & 3849 \\
\hline
\end{tabular}

Notes: ${ }^{\text {a }}$ The definition of the energy efficiency index is the energy consumption in the year in question to produce the total output in that year, divided by the energy consumption that would have resulted had the same production been made with energy efficiency in the year of reference (1989).

$\mathrm{b}$ In absolute terms.

Source: Based on Novem (1998) and Nogepa (1998). 
Oil companies are also affected by general measures to increase energy efficiency by, for example, increasing the use of co-generation. Natural gas is the dominant primary energy source in the Netherlands, with a share of about 50 per cent in total primary energy consumption, higher than any other International Energy Agency (IEA) country. Oil accounted for 36 per cent, coal for 12 per cent and nuclear energy for 2 per cent, while 1 per cent was net electricity imports (Slingerland, 1997). Due to the large share of natural gas, decentralised CHP has experienced a major boom since the late 1980s, partly due to climate policy: from a stable $1,500 \mathrm{MW}$ for many years to over 4,500 in 1995. The largest part consists of industrial CHP. There has also been a shift to gas in the fuel mix.

Gasuine is the venture responsible for the distribution of natural gas to electricity generation companies, distributors and some large industrial end users. It is partly state owned and partly owned by Exxon and Shell (Slingerland, 1997). In 1990, the distributors signed an agreement with the authorities that included an environmental action plan. This plan specified measures to be taken by the distribution companies that aimed to reduce $\mathrm{CO}_{2}$ emissions by 9 million tonnes by the year 2000. In 1994 , as a result of the second memorandum on energy conservation and NEPP 2, a new target was set at 17 million tonnes of $\mathrm{CO}_{2}$.

The next generation of LTAs spans the period 2000-2010. Since the most obvious measures were taken from 1989 to 2000, the range of measures and themes has been extended by focusing more closely on product efficiency and industrial cooperation across themes, such as transport. For energy-intensive industry including refineries - the LTAs will be replaced by so-called benchmark agreements (BA). The underlying logic is that Dutch energy-intensive industry cannot be pushed further than to become and remain the best in the world in terms of energy efficiency. If companies do not comply, the 1996 regulatory tax may be expanded to include energy-intensive industry.

Summing up, Dutch climate policy in the 1990s was characterised by relatively ambitious targets and increasingly vigorous policy instruments. Over time, this policy reduced uncertainty and affected Shell's climate strategy in two ways. First, Shell has been pressured by regulation on energy efficiency and negotiated 
agreements backed up by threats of regulatory taxes. Second, and more importantly, the company has been 'offered' new market opportunities by Dutch and EU policy on renewables. Notice that Dutch climate policy did not affect ExxonMobil's climate strategy even though ExxonMobil in the Netherlands has been exposed to the same climate policy as Shell. On the other hand, ExxonMobil has adapted to the climate policy in the Netherlands.

\section{Norway: ambiguous ambition}

Overall climate policy In the late 1980s, a green wave of public concern for the environment washed over Norway. In 1987, the UN Commission on Sustainable Development - led by the then prime minister, Gro Harlem Brundtland - released the Brundtland Report. The report, entitled Our Common Future, emphasised climate change as a major problem. Thus it came as no surprise that Norway was the first country in the world to adopt a unilateral stabilisation target for $\mathrm{CO}_{2}$ at 1989 levels by 2000 . Moreover, it was one of the first countries to introduce a $\mathrm{CO}_{2}$ tax covering mainly off-shore activities in 1991. This was met with strong opposition from the entire oil industry - including Statoil - even though Statoil was a fully state-owned company at the time.

Initial political enthusiasm, however, was soon replaced by pragmatic economic concerns. As a petroleum exporter, Norway was expecting a steep increase in its emissions of $\mathrm{CO}_{2}$ from petroleum activities (of the order of 60 per cent from 1989 to 2000), and stringent policy instruments could affect petroleum markets and export: almost one-third of total Norwegian export income came from petroleum export (Sydnes, 1996). Moreover, Norwegian energy production is based largely on hydroelectric power, which limits the country's potential to reduce emissions by changing energy consumption patterns and leaves the petroleum sector as one of the largest sources of domestic $\mathrm{CO}_{2}$ emissions. The structure of Norway's energy consumption and its dependence on petroleum exports led the country to seek solutions abroad rather than at home.

Norwegian climate policy can be divided into three phases. In the first phase, from the 1989 target to the 1992 Rio Summit, Norway developed a predominantly domestic strategy to combat 
climate change, linked with a high international profile. In the second phase, from 1992 to the Kyoto negotiations, the country's ambitions to combat GHG emissions domestically were significantly reduced. In the last phase, from Kyoto and beyond, Norway first adopted a more balanced strategy, acknowledging the need for domestic cuts in emissions combined with reductions abroad through flexible international arrangements. Thereafter, this policy drifted away from domestic cutbacks, before a national quota system that aimed to reduce domestic emissions was proposed in 2002.

The debate on a Norwegian $\mathrm{CO}_{2}$ target started in 1987 and culminated in the stabilisation target adopted in 1989. The ambitious target came as a result of a 'green beauty contest' between the political parties in the Storting (the Norwegian parliament) (Bergesen et al., 1995). ${ }^{35}$ With the adoption of the $\mathrm{CO}_{2}$ tax, Norway kept a high international profile during the INC negotiations starting in early 1991. In fact, Norway had leadership ambitions in international climate politics (Norwegian White Paper no. 46, 1988-1989). The Norwegian climate strategy was based on various principles including quantitative targets and timetables and flexible international arrangements. By the fall of 1991, flexibility overshadowed domestic cutbacks, and Norway was not prepared to sign an agreement that lacked joint implementation (Tenfjord, 1995). The UNFCCC resolved Norway's main concerns and the country ratified the Convention in 1993.

After Rio it became evident through the work on the national action plan that strong and far-reaching policy instruments were needed domestically to break the expected growth in GHGs by 2000. It was clear that the stabilisation target could only be reached by much tougher policy instruments than the $\mathrm{CO}_{2}$ tax (Reitan, 1998: 145). Simultaneously, public concern for environmental protection dropped significantly in the 1990s, along with the political willingness to cope with environmental problems in general (Farsund, 1997). In 1995, after a significant delay due to conflicting interests, Norway produced a White Paper on climate policy forming the basis for reporting to the UNFCCC. Here, the country officially gave up its stabilisation goal (Norwegian White Paper no. 41, 1994-1995). In the final approach to the Kyoto Protocol, Norway focused on differential commitments and flexibility mechanisms, and proposed that Annex I countries should 
commit themselves to a $10-15$ per cent emissions reduction by 2010. However, Norway did not want to take part in the reductions, and argued for emissions targets 5 per cent above 1990 level in 2008-2012. This number was, however, reduced to 1 per cent during the negotiations. Norway was actually among the few OECD countries that came to Kyoto without a national target (Andresen and Hals Butenschøn, 1999).

In 1997, the Labour government was replaced by a centre coalition. In 1998, this coaltion readopted a national target aiming to bring emissions back to 1989 levels by 2005. In a White Paper on climate-change policy (1997-1998), the centre coalition argued that a combination of domestic policy instruments and flexible international arrangements was needed to fulfil international commitments: 'it is neither desirable, adequate nor likely that the possibility to make use of flexible mechanisms will lead to a shift in main focus away from national measures' (St. meld. nr. 29, 1997-1998). ${ }^{36}$ Assisted by the Kyoto Protocol, the new minority centre coalition opposed gas-fired power plants that would result in increased domestic emissions, and suggested a tax of 100 Norwegian kr. per tonne of $\mathrm{CO}_{2}$ to cover - at a minimum - land-based industries exempt from the tax. This proposal was defeated in the Storting, and the majority decided instead to assess a future quota system allowing for free or very cheap quotas to the industry (Kasa, 1999). From 1998, the tax rates on oil and gas in the North Sea dropped significantly (Christiansen, 2000). Eventually, the centre coalition was forced to resign in 2000 , partly because of its opposition to gas-fired power plants. The new Labour government subsequently signalled a shift back to a predominantly international approach. This has recently been countered by yet another new government. In 2002, the new centre-conservative government proposed the implementation of an emissions trading system in 2005. The system focuses on companies exempted from the $\mathrm{CO}_{2}$ tax and aims at cutting domestic emissions and gaining experience before the Kyoto period from 2008 to 2012. By 2008, the Norwegian system will be expanded to all sectors as part of emissions trading under the Kyoto Protocol. ${ }^{37}$

Norwegian climate policy is set out in various White Papers released by different governments. In the spirit of sector integration, the Ministry of Oil and Energy also released a White Paper 
focusing on changing energy consumption and production in line with the Kyoto commitments (St. meld. nr. 29, 1998-1999). On paper, Norway has utilised and is planning to intensify the use of all main categories of policy instruments: regulations, economic instruments and voluntary agreements. In practice, however, Norway has relied heavily on the $\mathrm{CO}_{2}$ tax adopted in 1991. This covers about 60 per cent of the total $\mathrm{CO}_{2}$ emissions and some 90 per cent of $\mathrm{CO}_{2}$ emissions on the Norwegian Shelf. It is high compared to similar taxes that have been introduced or proposed in other counties, and it is based on various tax rates for different fuels: combustion and flaring of gas in the North Sea and use of petrol have been made subject to the highest tax rates. In the eyes of the public authorities, the experience with the tax is positive. For example, a study by Statistics Norway indicates that emissions from household, transport and stationary sources may have been 3-4 per cent lower than they would have been without the $\mathrm{CO}_{2}$ tax (Ministry of Environment, 1997).

Renewable energy (in addition to hydroelectric power) such as wave, wind, solar and bioenergy has never been high on the political agenda in Norway. In 1997, the first specific target for bioenergy and water-carried central heating was set for future market shares on new renewable energy. ${ }^{38}$ However, targets were not set for wind and solar. In contrast to many other European countries, such as the Netherlands, incentive-based instruments to increase the use of new renewable energy have been used to only a limited degree in Norway (Christiansen, 2002).

Direct regulation based on the State Pollution Control Authority (SFT) has been used as the main policy instrument for natural gas-fired power plants. Permits granted by the SFT for natural gas-fired power plants obliged Naturkraft - owned by Norsk Hydro, Statoil and Statkraft - to slash emissions of $\mathrm{CO}_{2}$ by half and $\mathrm{NO}_{\mathrm{x}}$ by 90 per cent. These strict ceilings on emissions would have weakened the project's profitability based on current technology. In 1996, Naturkraft applied for a licence to build two gas-fired power stations. This application triggered a fierce environmental struggle in Norway that highlighted the tension between national and international reductions. The opponents took the position that new plants would increase total national emissions. The proponents argued that Norwegian gas could replace Danish coal and Swedish nuclear power. The Labour 
government supported the new plants and thought that Norwegian gas could be credited as joint implementation. Their problem was to convince the opponents that the gas would actually replace, and not be additional to, coal. The new centre coalition government combined its proposal for tax extension with opposition to gas power based on current technology. After the new Labour government took office in 2000, Naturkraft was granted permission to go ahead, but electricity prices have been too low to make any gas-fired power plants profitable.

In conclusion, Norway has until now relied almost exclusively on the $\mathrm{CO}_{2}$ tax in its national climate policy. Additional policy instruments are mainly on the drawing board. The recently proposed national quota system aims at covering land-based companies exempted from the tax. In retrospect, climate targets and policy instruments fluctuated in their level of ambition during the 1990s, providing target groups with a highly unpredictable climate policy context. At a general level, this corresponds well with Statoil's ambiguous climate strategy.

Policy instruments and the oil industry Energy efficiency has increased significantly in the Norwegian off-shore petroleum sector since 1990: emissions per produced oil equivalent have been reduced by 30 per cent since 1990 and those from flaring dropped by 17 per cent between 1990 and 1996. On the other hand, total emissions of GHGs have increased by some 30 per cent in the same period, and emissions are expected to increase significantly in the future. Important reasons for the expected growth are increased production and increased energy intensiveness in the production process, since such production is moving north - from the North Sea to the Norwegian Sea.

The $\mathrm{CO}_{2}$ tax introduced in 1991 is the most important policy instrument in the Norwegian petroleum sector. While most landbased sectors are exempt from the tax, it covers almost 90 per cent of the $\mathrm{CO}_{2}$ emissions off-shore. The tax level for burning oil and gas used to be above 300 Norwegian kr. per tonne of $\mathrm{CO}_{2}$, before it started to drop in 1998. In 1997, Statoil launched its ' $\mathrm{CO}_{2}$ programme' with the objective of estimating costs of implementing abatement measures on off-shore as well as land-based plants (see chapter 3). More than 50 technical options for emissions abatement on off-shore installations have been assessed, and 
pilot programmes were set up. According to Christiansen (2000), the $\mathrm{CO}_{2}$ tax may have been important for decisions to implement abatement measures on off-shore installations, but taxes offer at most only a partial explanation for Statoil's $\mathrm{CO}_{2}$ programme. Fluctuations in tax rates and recurring political discussions on replacing taxes with emissions trading have generally created uncertainty and hesitancy to invest in costly abatement measures. Since the 1970s, gas flaring has been regulated through flaring permits authorised by the Petroleum Act. While this system has led to low GHG emissions from flaring and cold ventilation compared to other countries, it has been motivated by resourcemanagement reasons rather than climate-change considerations.

While Statoil has been somewhat influenced by the $\mathrm{CO}_{2}$ tax to implement abatement measures, Norwegian policy on renewables has not provided Statoil with sufficiently interesting opportunities to become an energy company. Targets and measures on new renewable energy have stimulated only limited industrial development in Norway: only a few small firms are engaged in this sector and the rate of new entries in the new renewables branch is low (Christiansen, 2002). Except for some small projects on biomass and fuel cells, Statoil has mainly focused on abatement measures in its climate strategy.

In sum, the principal climate policy instrument in the Norwegian petroleum sector is the $\mathrm{CO}_{2}$ tax introduced in 1991. This has had some impact on Statoil's climate strategy. However, Norwegian climate policy during the 1990s fluctuated in terms of targets and policy instruments. This unpredictability has made a clear proactive strategy difficult for Statoil and other target groups. In addition, public initiatives in the field of renewable energy other than hydroelectric power have to only a very limited extent provided Statoil with commercially interesting market opportunities in clean energy.

\section{Comparison of climate policy}

US climate policy has exposed its oil industry to little pressure and few market opportunities in renewables. In general, conflicting political interests sending ambiguous signals to target groups have marked US climate policy. The Clinton-Gore administration sought to develop a viable climate policy, but Congress on several occasions blocked any progress: the failure of the BTU tax as well as 
insufficient funding for the public voluntary programmes are cases in point. Besides $\mathrm{R} \& \mathrm{D}$, the main policy instrument in US climate policy has been genuinely voluntary programmes that have created little pressure. However, these programmes aim at creating markets for existing and close to existing technologies, thus providing industry with some opportunities. Nevertheless, ExxonMobil has largely neglected the public voluntary programmes.

In contrast to the US, there has been a broad-based political consensus on climate policy in the Netherlands. Even though there has been some political disagreement on specific reduction targets, policy instruments have been gradually stepped up over time. The 1999 climate-policy plan reduced uncertainty and shaped expectations for the future. Shell has been exposed to relatively strong regulatory pressure through the combination of regulation to improve energy efficiency and LTAs, plus the threat of rising taxes. Still, Shell's climate strategy appears to have been influenced most by ambitious targets and measures aimed at promoting market opportunities for renewable energy. ExxonMobil has been exposed to the same climate policy as Shell in the Netherlands. This observation supports the assumption that home-base countries are particularly important for corporate climate strategies.

Shell has its backbone in the Netherlands, but Shell International is actually located in the UK. While a systematic scrutiny of the UK goes beyond the scope of this chapter, we should note that the climate policy of the UK pulls in the same direction as Dutch policies, but for different reasons. The UK has reduced its $\mathrm{CO}_{2}$ emissions and developed an ambitious climate policy due to the closure of coal mines and the shift to natural gas for economic reasons. In 2000, the UK launched its Climate Change Programme, aimed at going well beyond its Kyoto commitments to reduce GHG emissions by 12.5 per cent below 1990 levels. As part of the programme, the UK has launched an emissions trading scheme in which Shell UK and BP are major participants. ${ }^{39}$

Norwegian climate policy can be placed in between those of the US and the Netherlands. As in the US, there have been conflicting political interests that have led to fluctuating targets and policy instruments. This has created an ambiguous climate policy, which has made a proactive strategy difficult for Statoil. 
The main difference from the US is the $\mathrm{CO}_{2}$ tax, which has stimulated some abatement efforts. In contrast to the Netherlands, public initiatives to stimulate renewable energy in addition to hydroelectric power have not provided Statoil with sufficiently interesting market opportunities.

\section{Linking supply and demand}

People and governments, or states and societies, are linked together by institutions that channel influence. One important channel is the corporative one, in which industry, environmental organisations and governmental decision-makers meet to consult, negotiate or collaborate. Corporations do not only respond to social demand and governmental policies, they represent in themselves a social interest group with a potential to influence governmental policies. While this section will mainly focus on how political institutions affect corporate strategies, the question of how corporations exercise their influence will be more fully addressed in the next chapter.

There are two main stereotypic approaches to organising the relationship between state and industry. First, there is a conflictoriented approach, which aims to avoid regulatory capture. Here, the state imposes standards and regulations on target groups that tend to be excluded from the decision-making process. This approach is likely to result in opposition from industry and a reactive corporate strategy. Second, there is a collaborative approach based on target-group responsibility, whereby the government consults and negotiates goals and policy instruments with target groups included in the decision-making process. This approach is likely to lead to a proactive strategy. As noted in chapter 2 , it is reasonable to assume that these approaches will lead to different corporate strategies, but not necessarily different levels of environmental effectiveness. A cooperative approach is likely to lead to successful implementation at the expense of more lenient goals and policy instruments.

In this section, we will focus on the political institutions that link states and industry. Since climate change is a relatively new environmental challenge, we will include general cooperative traditions concerning environmental protection in general, as well as climate policy in particular. 
The US: conflict-oriented approach

Confrontation between target groups and regulating agencies has been institutionalised in the US since the 1970s. When the EPA was established in 1970 to implement environmental legislation, Congress was concerned about 'regulatory capture', i.e. that the regulated would take control over the regulator. Legislators guarded against this by various means, which biased the EPA towards environmentalists rather than industrialists (Wallace, 1995). Concern over regulatory capture is widespread in the US, and business people are routinely excluded from regulated topics they have previously worked in.

In the mid-1980s, Vogel (1986: 21) described the US style of regulation as the most rigid and rule-oriented found in industrial society: the US makes no use of industry self-regulation, makes much use of the courts, restricts administrative discretion as much as possible and focuses on conflict in environmental policy. Ten years later, Wallace (1995: 111) still maintained that 'the adversarial, legalistic approach to environmental issues has produced an inflexible, fragmented and confused regulatory system, which stifles innovation and so frustrates industry that opposition to environmental goals seems preferable to seeking creative solutions'. The image of the US regulatory system is now changing, but the backbone of US regulatory models remains essentially intact (Dannenmaier and Cohen, 2000).

US environmental legislation is based on a number of separate acts, each focusing on a single medium: water, air and soil pollution. Each act is very detailed and leaves little flexibility with respect to implementation: compliance with specific standards represents the core of environmental policy. The emphasis placed on compliance by the public authorities is in turn mirrored in ExxonMobil's environmental policy (see chapter 3). While the US oil industry faces very lenient climate policy instruments, it is nevertheless subjected to strict environmental regulation in other areas of environmental degradation (water and air pollution) perhaps even more so than in any other part of the world (Skea, 1992). Oil field exploration production is regulated at the federal level by no fewer than six laws, including the Oil Pollution Act of 1990 and the Clean Air Act as amended in 1990. In addition, federal and state regulations frequently overlap. The EPA has been developing new standards under the Clean Water Act in 
relation to both off-shore and on-shore exploration and production. According to the API, the petroleum industry will be spending US\$26-33 billion annually to comply with the federal environmental regulations alone (Kotvis, 1994). At the other end, standards for motor vehicle design and fuel quality have a significant impact on the oil industry. For example, corporate average fuel economy standards were initiated after the energy crisis of 1974 to help reduce US reliance upon foreign oil (Kirby, 1995).

The API paints a dark picture of an industry under severe pressure, partly due to the shape and content of environmental regulations. Employment has declined significantly since 1980, profit rates have declined, US oil companies have shifted more of their activities to locations outside the US and almost half of the refineries have been closed since 1980 (Perkins, 1999). According to the Department of Energy (DoE), the oil industry spends as much on environmental protection as it spends searching for new domestic supplies of oil and natural gas. That amounts to US\$10.6 billion a year, nearly twice the budget of the US EPA. ${ }^{40}$

Adversarial behaviour patterns are further stimulated by the court system. The threat of litigation leads to a lack of trust between regulators and the regulated, making it difficult to establish cooperative patterns. Most environmental laws have given citizens the legal right to use civil action against any person, including the administration, for failing to implement legal environmental obligations. Industry or environmental groups have on many occasions challenged the EPA. The costs of litigation sometimes even outstrip the costs of clean-up efforts (Wallace, 1995). The role of the courts in US environmental policy is also one important reason why the administration started with public voluntary programmes in climate policy: mandatory policy instruments would work against the need for swift action. For example, it took almost 10 years from the early 1980s to update the 1970 Clean Air Act. According to the API, the slowness of the US decision-making system, as well as the significant difference in how industry and government interact in Europe and the US, are very important factors explaining the difference in climate strategies between US and European oil companies. ${ }^{41}$

After an anti-environment stance under President Reagan in the 1980s, there was an effort to push US environmental policy in a more collaborative direction in the 1990s. For example, 
President Clinton immediately established the President's Council on Sustainable Development (DSP, 1997). This council comprised 35 leaders from industry, all levels of government and environmental organisations. One important task for the Council was to develop agreement on general goals related to sustainable development. However, traditional models of interaction are not changed easily. There was generally little cooperation and consultation between the administration and industry groups before the Kyoto negotiations. In particular, the American oil industry and ExxonMobil were excluded from active participation in the decision-making process leading up to the initial US support of the Protocol. The API made an effort on several occasions to communicate with the administration. The API's perception is that the Clinton-Gore administration showed no interest in cooperating with 'Big Oil'. 42

While access to the administration has been limited, the openness and structure of the US government provide ample room for interested parties to influence the policy process, particularly in the Congress (Skolnikoff, 1997). Fierce lobby campaigns based on funding political allies and media campaigns are a prominent part of US political culture (Kolk, 2001). Industry lobbying has also been a prominent part of energy and climate policy (Hatch, 1993). The Constitution severely restricts the freedom of action of the executive branch, that is, the administration. Like other policies, US climate policy is formulated and implemented within a political system based on the US Constitution. ${ }^{43}$ To become law, a bill must be approved by the president and both Houses of Congress. Congress can override a presidential veto by a twothirds vote in the House of Representatives and the Senate. Since climate change touches upon many core US interests, lobbying is the main channel for interested actors. The House of Representatives and the Senate are made up of a number of committees and subcommittees that deal with general issues. Their competence on environmental matters overlaps, and environmental legislation is dealt with by many committees. A large industry lobby exploits this fragmented structure by influencing decision-makers and assisting them with drafting legislation.

As the largest private oil company in the world, ExxonMobil plays an influential, if not a dominating, role within the API, which in turn plays an influential role in the GCC. From 1989, 
this organisation represented and voiced the opposition of a broad spectrum of business interests in the US, including labour, agricultural and industrial organisations. The GCC has directed and coordinated a massive opposition to US ratification from its tiny office in Washington, DC, a stone's throw away from Congress, where the coalition had a strong ally in the Republican majority of the Senate (until May 2001). Contributions to party funds provide a key channel of influence for the US fossil-fuel industries. According to Greenpeace International, the petroleum industry donated US\$53.4 million to US election candidates and their political parties between 1991 and 1996 (Levy and Newell, 2000). Since 1999, ExxonMobil has been one of the largest US contributors to Republican candidates. ${ }^{44}$

The fate of the 1992 BTU tax is quite illustrative of the influence of US lobby organisations (Agrawala and Andresen, 1999). When the tax proposal came to the Senate Finance Committee in 1993, it was clear that it could be killed before a full vote in Senate if one Democrat voted against it. The API and a wide range of other industry interests mobilised by forming the American Energy Alliance in order to defeat the tax. The alliance hired a PR firm - Burson-Marsteller - which was able to put local pressure on Democrats through the media. Senator Boren from Oklahoma was the first to give in, thus sinking the tax proposal. According to the API, much of their resistance to the climate policy of the Clinton-Gore administration can be traced back to this event.

From 1993 to 2000, the Clinton-Gore administration tried to develop a viable climate policy at home as well as internationally by keeping 'Big Oil' at arm's length, while consulting with the green movement. This strategy proved unsuccessful because of Congressional resistance, partly as a result of intensive lobbying by the fossil-fuel industry. In 2001, George W. Bush Jr took office and the oil industry enjoyed an 'access bonanza' at the expense of consumers, according to observers. ${ }^{45}$ As noted, ExxonMobil has been one of the most generous political donors in the US. In return, energy officials representing the Bush administration have met only with ExxonMobil and other energy industry leaders, while at the same time deliberately excluding the green movement. ${ }^{46}$

The US political system is to a large extent based on an adversarial approach to the development of environmental regulation. 
Under the Clinton-Gore administration, the US oil industry, with ExxonMobil in the lead, was to a large extent excluded from participation in developing US climate policy. ExxonMobil and the API perceived the 1992 BTU tax as extremely provocative. This event in particular strengthened ExxonMobil's reactive climate strategy, rather than stimulating a search for constructive cooperation. And ExxonMobil and most of the fossil-fuel lobby had ample room for influencing US climate policy. After the shift in presidency in 2001, ExxonMobil and the Bush Jr administration have had complementary - if not identical - interests in a lenient US climate policy.

\section{The Netherlands: consensual approach}

In contrast to the US, the Dutch policy system has strong neocorporatist qualities. The Dutch negotiated and consensus-building democracy is based on a strong state with strong social interests. This consensual policy style has a long tradition in the Netherlands, although its shape and content have changed over time. For example, Arents (1999) goes so far as to claim that consensus building is even institutionalised in the Dutch language and that the Dutch prefer a consensual approach almost out of habit. Even though the peak of Dutch consensual corporatism can be traced back to the 1950s and early 1960s, negotiated agreements with industry during the 1990s still represent visible signs of this tradition.

Bargaining and cooperation with interest groups, both formally and informally, are particularly evident in the environmental sector, including climate policy. The Netherlands has developed a target-group approach based on the idea of raising environmental concerns and social responsibility among those actors causing the problems in the first place. In return, the government lets the target groups have their say in the making and implementation of environmental policy and pays serious attention to their needs.

The use of negotiated agreements in the Netherlands is part of a comprehensive environmental policy in which target groups have actively participated all the way. The Ministry of Environment started developing a consensual approach on the basis of the Environmental Protection Act of 1980. In 1981, the Council for the Environment was established, providing environ- 
mental organisations, industry and other actors with a formal channel for influencing environmental policy (Liefferink, 1995). The ministries' cooperative approach was further developed in the indicative multi-year programmes for the environment, which started in 1984. The way in which NEPP 1 was developed represents a deepening and a continuation of the target-group approach. In a relatively short time, this approach led to approximately 100 negotiated agreements, or covenants as the Dutch call them, covering all major industrial sectors. NEPP 1 was supposed to be published in 1987, but was delayed for two years owing to the ambition of seeking agreement with all parties affected by specific goals and policy instruments (Bennett, 1991).

Shortly after the adoption of NEPP 1, the Committee on Environment and Industry was established by the major actors representing the authorities and industry (Suurland, 1994). Fourteen industrial sectors were selected as priority target groups, involving some 12,000 companies responsible for over 90 per cent of industrial pollution. On the basis of the NEPP targets, the Ministry of Economic Affairs developed a programme aiming to increase energy efficiency in industry by 20 per cent by the year 2000. LTAs are signed by the sector association, individual firms and the Minister of Economic Affairs. All agreements include an objective, energy-conservation strategy, energy-saving plans for individual firms, monitoring and statement of duration.

Negotiations between the government and industry - particularly the Netherlands Employers' Association (VNO) - produced a broad-based consensus on ambitious targets, including the $\mathrm{CO}_{2}$ stabilisation target and the need for increasing energy efficiency by 20 per cent between 1990 and 2000. This agreement was based on differentiated targets between companies within the same branches. In homogeneous branches, agreements were concluded between the branch organisations and the government in order to reduce costs. As could be expected, the involvement of target groups forced the government to agree to less stringent goals than it otherwise would have proposed (Weale, 1992).

In contrast to the US, the Dutch oil and gas industry has traditionally operated with a high level of discretion concerning both the identification of problems and the implementation of measures (MILJØSOK, 1996). Accordingly, the Dutch oil industry has a more positive experience with environmental regulation. Air 
pollution from off-shore activities has been weakly regulated compared to on-shore ones, and the authorities have had few sanctioning opportunities in cases of non-compliance. Standards and technology requirements have been negotiated within the framework of the permit system.

The Dutch consensual tradition and target-group approach have affected the way Shell operates as a company. ${ }^{47}$ Until 1995, the Shell Group was based on an unusually complex organisational structure. Complexity was further increased by the Group's emphasis on reaching decisions by consensus, which implied that decision-making involved an unusually high level of internal discussion (see chapter 4). In essence, Shell mirrored the Dutch consociate democracy. The Dutch way of organising contact between industry and government has also led to close cooperation between Shell Netherlands and the authorities. According to Shell, the company has a very good relationship with the Dutch government on environmental matters. ${ }^{48}$ Cooperation between Shell and the authorities takes place in formal committees as well as informally. This relationship does not, however, imply that Shell and the government have identical interests in all matters. Shell and other Dutch companies have had their disagreements on climate policy, particularly related to the regulatory tax. Like most other companies, Shell dislikes environmental taxes.

In 1989, there was a change in the Dutch government leading to a revision of the first NEPP. The new plan - NEPP Plus disturbed the original platform of consensus on which the first NEPP was based. NEPP Plus introduced a more stringent target and emphasised economic instruments. The plan was criticised both for going too far and for not going far enough. Industrial and agricultural target groups warned about moving too far ahead of other EU countries. On the other hand, the environmental movement thought that the new goals and instruments were insufficient to establish sustainable development. The new $\mathrm{CO}_{2}$ reduction target and the emphasis on economic policy instruments had not been agreed upon with industry, including the oil industry. Industry ferociously resisted the upcoming tax, and the VNO withdrew its formal support for NEPP Plus (Wallace, 1995). While this setback may have had consequences for the credibility of the climate target, it had no negative consequences for the LTAs adopted in the field of energy efficiency. Since 1991, 
29 agreements have been signed, representing about 90 per cent of total energy use in industry, and the 20 per cent energy efficiency target is in sight (Skjærseth, 2000).

While employer, car and oil associations supported the energyefficiency targets, they continued their fight against the regulatory tax, arguing that financial instruments should be introduced only at the EU level. At the same time, the same interest groups lobbied intensively against the EU-proposed carbon/energy tax through their respective Eurofederations: the EU tax proposal eventually failed in the Council of Ministers shortly before the 1992 Rio conference. The European Petroleum Industry Association (EUROPIA) expressed the strongest reservations concerning the creation of a tax on oil products. Shell was a key actor at both the Dutch and the EU levels and pointed to a contradiction between $\mathrm{SO}_{2}$ and $\mathrm{CO}_{2}$ reduction targets. In order to reduce one tonne of $\mathrm{SO}_{2}$ emissions, refineries were forced to produce 10 additional tonnes of $\mathrm{CO}_{2}$ emissions (Schenkel, 1998). This argument is still being used by EUROPIA, even though it has shifted to a more positive stand on the need to combat climate change. ${ }^{49}$ In the end, the oil industry and other interests won a partial victory. On 1 January 1996, a combined carbon/energy tax was introduced in the Netherlands unilaterally. It is levied on the use of natural gas, heavy fuel oil, diesel oil, liquified petroleum gas and electricity. Natural gas and electricity produced from renewable sources are exempt. On the other hand, the biggest industrial users pay only a third of the price that small users - households and small and medium-sized firms - have to pay.

In sum, the Netherlands has, in contrast to the US, a consensual tradition, and it has based its environmental and climate policy on close cooperation between target groups and the government. This has affected the corporate structure of Shell and has led to good relations between Shell and the Dutch government, which in turn has stimulated a proactive strategy. However, like most other corporations, Shell opposed the regulatory tax.

\section{Norway: a mixed approach}

Like the Netherlands, Norway is frequently classified as a neocorporatist country where institutionalised rights of participation are provided to non-governmental organisations in all phases of governmental policy. However, Norwegian environmental policy 
has been based neither on extensive formal target-group participation, nor on exclusion. In contrast to the adversarial US approach, the Norwegian counterpart to the EPA, the SFT, has traditionally given priority to industry in its licensing policy, although priority given to environmental protection interests has increased (Gjerde, 1992). In contrast to the comprehensive and inclusive Dutch environmental programmes, formal channels for participation in Norway are less developed and more ad hoc. In addition, there is general scepticism towards the use of voluntary agreements in Norway. They have never made their breakthrough in Norwegian climate policy, in contrast to many other OECD countries. ${ }^{50}$

Statoil is partly owned by the Norwegian state and has traditionally served as a state instrument for protecting Norwegian petroleum interests. The link between Statoil and the state is thus particularly strong, and Statoil has a privileged status as a 'core' insider. However, Statoil has increasingly been treated on equal terms with other oil companies by the licensing system that regulates petroleum operations in Norway (Rudsar, 1999). And, as we will see, the relationship between the government and Statoil in climate policy can be characterised by both conflict and cooperation.

The Petroleum Act and the Pollution Control Act regulate emissions other than those of GHGs to the sea and air. Norway's Petroleum Act requires environmental impact assessment to be carried out at several stages in petroleum operations - from the opening of an area to the disposing of abandoned installations. On the basis of such assessments, the Storting undertakes an assessment of the pros and cons of pursuing operations in the area. Discharges to the sea are regulated by the Pollution Control Act in the form of individual licences. The principal rule is zero discharges of hazardous substances, in line with the 1995 North Sea Declaration. However, the Norwegian off-shore regulatory regime is generally described as flexible in practice: standards are general and leave significant scope for interpretation on a caseby-case basis. Sanctions are rare and compliance is mainly based on internal control conducted by the companies themselves (MILJØSOK, 1996:100). As in the Netherlands, the oil industry appears generally satisfied with 'traditional' environmental regulation. 
When the Norwegian climate target was discussed in the parliament in 1989, industry did not show much interest in the issue, and the Norwegian Employers' Association (NHO) did not have any strong opinions (Bolstad, 1993). In the same year, the Environmental Tax Committee was established to assess the foundation for a $\mathrm{CO}_{2}$ tax. This committee was expert-dominated and did not include representatives from interest organisations. Moreover, the first report, which provided the basis for the 1991 tax, was not made public. Thus, industry and environmental organisations were effectively prevented from formally influencing the premises for the tax. And the parliamentary decision to implement the tax mainly on off-shore activities was made in the face of strong resistance from the entire petroleum industry (Reitan, 1998; Kasa, 2000). However, the strongest resistance came from energy-intensive land-based industry fearing an expansion of the tax. This included Statoil and another large government-owned company with a big petroleum division, Norsk Hydro. These companies argued that neither gas-fired power plants nor planned methanol plants would be economically viable with a $\mathrm{CO}_{2}$ tax. Nevertheless, the most important economic sector for Norway and the Norwegian oil industry - off-shore oil and gas production - lost in its opposition to the $\mathrm{CO}_{2}$ tax, while the energy-intensive land-based industries won.

In 1994, the Green Tax Commission was established to assess a transformation from taxes on labour to taxes on pollution. Extension of the $\mathrm{CO}_{2}$ tax to land-based industries rapidly became one core topic within the commission. In contrast to the Environmental Tax Committee, the Green Tax Commission was based on interest representation, including the Naturvernforbundet and Norsk Hydro. The Naturvernforbund, the Ministry of Environment and the Ministry of Finance preferred a comprehensive tax based on environmental cost-effectiveness concerns. The industry, represented by $\mathrm{NHO}$, the largest labour union (Landsorganisasjonen) and the Ministry for Trade and Industries (in which the previous Ministry of Oil and Energy was included), was more concerned about cost distribution than cost-effectiveness. It argued that exports and employment would decline particularly in small rural towns heavily dependent on energy- intensive industries. In the end, prime minister Gro Harlem Brundtland (Labour) decided to block an extension of the tax. One important reason for 
her decision was the planned gas power plants (Kasa and Malvik, 2000).

In 1997, a new centre government replaced Labour. The new government opposed gas power, and favoured an extension of the $\mathrm{CO}_{2}$ tax. The Ministry of Trade and Industry and the Ministry of Petroleum and Energy were split and largely decoupled from their traditionally close relationship with the industry under the Labour government. However, industry interests changed their strategy and lobbied towards the political parties in the Storting. Eventually, a majority voted against extending the tax and decided to prioritise an emission trading system (Kasa and Malvik, 2000). In short, Statoil was to a large extent formally excluded from the Norwegian $\mathrm{CO}_{2}$ tax process, and the $\mathrm{CO}_{2}$ tax was adopted and implemented against the interests of Statoil.

After the first round of wrangling about the $\mathrm{CO}_{2}$ tax, Statoil and the Ministry of Petroleum and Energy initiated in 1995 a new cooperative forum, MILJØSOK, in order to improve environmental performance on the Norwegian continental shelf. This forum aimed to improve cooperation primarily between the oil industry and the authorities in the field of the environment based on the NORSOK model. NORSOK was established in 1993 to improve the competitive standing of the Norwegian offshore sector. MILJØSOK represented a voluntary approach in which Statoil held a key position through its leadership of the steering group (MILJØSOK, 1996). The objective of MILJØSOK was to contribute to a more effective environmental strategy as well as improve cooperation between the authorities and the industry. It operated as a 'signpost' which reduced uncertainty and stimulated innovative solutions (Christiansen, 2000). A final report from phase one concluded that tax rates should be reduced in favour of establishing binding forms of cooperation, such as negotiated agreements. Transition to cleaner technologies was identified as the most cost-effective approach to problem solving in this sector.

MILJØSOK initiated a second phase in 1997 (MILJØSOK, 2000). In this phase, ambition levels were significantly reduced, and it became evident that radical measures were needed to counterbalance expected increases in emissions owing to higher production levels and higher energy needs. Nevertheless, according to the head of Statoil's $\mathrm{CO}_{2}$ programme, the MILJØSOK 
initiative played an equally if not more important role than the $\mathrm{CO}_{2}$ tax for Statoil's climate strategy. Decisions on more energyefficient power-generation technology have been strongly influenced by the findings of the MILJØSOK initiative (Christiansen, 2000).

An effort was also made to reduce emissions of non-methane volatile organic compounds (NMVOC) from shuttle tankers. The formation of ground-level ozone is, however, the main problem associated with NMVOC in combination with $\mathrm{NO}_{\mathrm{x}}$. Negotiations began in 1998 between the Norwegian authorities and the oil industry on an agreement for reducing NMVOC emissions from shuttle tankers loading crude oil. Such activities account for about 60 per cent of total NMVOC emissions in Norway. The parties comprised the Ministry of Environment plus the oil industry, which in turn was composed of 18 companies with licence interest on the Norwegian continental shelf. The aim of the agreement was to apply best available technology (BAT) on all 20 relevant ships by 2005. In total, this would cost about 2 billion Norwegian kr. and lead to reductions of the order of 70 per cent from each ship. Introduction of BAT on the shuttle tankers is considered to be the most effective means in terms of both costs and effects in the petroleum sector (Dragsund et al., 1999). In the end, however, major US oil companies suddenly refused to support the deal and the agreement collapsed. This example shows that multinational companies can affect governmental policies of host countries as well as home-base countries. Moreover, it points to the link between policy instruments and the climate strategies of multinational target groups (see chapter 7).

Norway can be placed between the US and the Netherlands with respect to political institutions regulating state-industry relationships. In climate policy, the foundation for the $\mathrm{CO}_{2} \operatorname{tax}$ was shaped without formal participation by Statoil and adopted in spite of Statoil's interests. On the other hand, Statoil has been the key oil company participant in the MILJØSOK initiative, which aimed to improve cooperation between companies and the authorities. According to Statoil, this cooperative forum has proved as important for the company's climate strategy as has the tax initiative. 


\section{Conclusion}

To recapitulate, the DP model was based on the assumption that even multinational companies are particularly influenced by their home-base countries. Companies closely tied to home-base countries with a high social demand for environmental quality, a governmental supply of ambitious climate policy, and political institutions that promote cooperation and consensus seeking with target groups tend to adopt a more proactive strategy. Conversely, companies with home-base countries characterised by a relatively low social demand, weak climate policy and political institutions based on conflict and imposition tend to adopt a more reactive response. The results are presented in table 5.3.

Table 5.3 The DP model: expected versus actual strategies in relative terms

\begin{tabular}{|c|c|c|c|c|c|}
\hline $\begin{array}{l}\text { Home } \\
\text { country }\end{array}$ & $\begin{array}{l}\text { Social } \\
\text { demand }\end{array}$ & $\begin{array}{l}\text { Governmental } \\
\text { supply }\end{array}$ & $\begin{array}{l}\text { Political } \\
\text { institutions }\end{array}$ & $\begin{array}{l}\text { Predicted } \\
\text { strategy }\end{array}$ & $\begin{array}{l}\text { Actual } \\
\text { strategy }\end{array}$ \\
\hline The & High/ & & & & \\
\hline Netherlands & Medium & High & Consensus & Proactive & Proactive \\
\hline \multirow[t]{2}{*}{ Norway } & Medium/ & & & & \\
\hline & Low & Medium & Mixed & Intermediate & Intermediate \\
\hline US & Low & Low & Conflict & Reactive & Reactive \\
\hline
\end{tabular}

Table 5.3 shows that the propositions derived from the DP model gain strong empirical support evaluated in terms of pattern-matching: all three cases roughly match the expectations derived from the DP model. Differences in national political context vary systematically with differences in corporate climate strategies. Variation in social demand, governmental supply and political institutions linking demand and supply all apparently matter in explaining the climate strategies of ExxonMobil, Shell and Statoil. Judging the DP model in terms of the tenability of the propositions derived from it, we can conclude that we have had a high degree of success in predicting corporate climate strategies.

Correlation, however, is not the same as causation. The causal patterns linking domestic political context to corporate strategy appear long and even indirect. Below, we will first recapitulate the main relationships between the DP model and corporate strategies before causal patterns and mechanisms are critically examined. 
The relationships between national political context and corporate climate strategy appear strong. Shell has its roots in the Netherlands and has adopted a proactive climate strategy. The Dutch population expresses the highest demand for climate policy, the Netherlands has adopted the most ambitious climate policy, and the political institutions are based on cooperation and consensus-seeking between the state and industry. This pattern appears robust even if we control for the fact that Shell International is located in the UK. In contrast, the North American company ExxonMobil has adopted a reactive climate strategy within a significantly different political context. North Americans apparently express less concern about climate change, US climate policy is weak in terms of goals and policy instruments, and political institutions channelling state-industry influence can be characterised as adversarial. In between, we find Statoil and Norway. Statoil has adopted an ambiguous climate strategy which can be characterised as intermediate, i.e. neither reactive nor proactive. The Norwegian population has fluctuated significantly in its concern for climate change, and so has Norwegian climate policy. In addition, political institutions linking state and society are mixed, i.e. based either on close cooperation or on conflict. Table 5.3 also depicts a strong relationship between social demand and governmental supply of climate policy. While social demand matters for climate policy, other factors such as energy-economic circumstances are probably equally important. Nevertheless, social demand appears to affect corporate strategy both directly through consumer behaviour and indirectly by influencing public policy.

At the level of general patterns, we have thus no empirical observations supporting the assumption that state-owned companies are more likely than private companies to choose a climate strategy in accordance with the position of their governmental owners. The relationship between home-country context and climate strategies appears to be strong independent of type of ownership. This observation is also supported by the fact that the Norwegian $\mathrm{CO}_{2}$ tax was introduced in spite of opposition from the state-owned company representing the strongest economic sector in Norway: Statoil. Looking also at the introduction of the Dutch regulatory tax against the will of Shell and other Dutch energy-intensive industries, we see that the state can maintain a 
certain degree of independence from business interests in climate policy. The Clinton-Gore administration also made an effort to distance itself from ExxonMobil and US fossil-fuel industries by proposing the BTU tax. In this case, however, the government was defeated by industry lobbying directed at Congress.

Below, we will take a critical look at the causal mechanisms and patterns linking the political context of the companies' homebases to corporate climate strategies. Let us start with the observations supporting a close link between the Netherlands and Shell. On the one hand, we have strong indications that Shell has been particularly sensitive to the Dutch societal and political context. The company has used the Netherlands as a sort of test case for predicting changes in energy carriers in the future. A relatively high social demand is in line with Shell's scenarios and probably linked to its strategy on renewables. However, Shell's vulnerability to consumer campaigns and loss of reputation must be understood in the context of the company's experiences with boycotts linked to South Africa, Nigeria and Brent Spar, which have increased the company's sensitivity to societal pressure. Accordingly, Shell's climate strategy along this dimension should be looked at in the light of the interface between political context and corporate specific events (see chapter 4). Dutch supply of climate policy in the 1990s was characterised by relatively ambitious targets and the adoption of increasingly vigorous policy instruments. Regulation and negotiated agreements on energy efficiency backed up by threats of taxes put some pressure on Shell. However, Dutch policies on renewables appear more directly linked to the company's climate strategy. An ambitious governmental policy on renewables combined with a social demand for clean energy provided Shell with an anticipation of new market opportunities. Cooperative political institutions also contributed to constructive relationships between the Dutch authorities and Shell. In essence, the link between Dutch national political context and Shell's proactive climate strategy is marked by a positive interplay between pressures and opportunities provided by social demand, governmental supply and political institutions linking demand and supply. Moreover, it is marked by a positive interplay between political context and companyspecific factors.

On the other hand, this pattern of observation does not appear 
sufficiently persuasive. Although Shell has its roots in the Netherlands, the country represents only a part of the company's operations and activities. Shell operates in more than 135 countries, and the main markets are located in Europe and the US. Relying on developments in the Netherlands alone thus appears too risky. In addition, the DP model as applied to the Netherlands does not account sufficiently well for the changes witnessed in climate strategy. Shell changed from a reactive to proactive company around 1997-1998 and was a member of the strongest and most aggressive US-based anti-climate lobby group - the GCC - until 1998. Social demand peaked around the Rio conference in 1992 and then declined somewhat. Dutch climate policy progressed steadily in terms of targets and policy instruments during the 1990s, without any dramatic changes. The question then becomes whether the Dutch target on renewables adopted in 1995 and the Dutch LTA on energy efficiency concluded in 1996 created sufficient pressure and opportunities to trigger a turnabout in Shell's climate strategy. Although it is difficult to judge, we believe that these changes in policy were important, but not sufficient to push and pull a large multinational oil company towards a more proactive strategy.

Turning to the US and ExxonMobil, we find some answers but also some new questions. In the 1990s, the relationship between ExxonMobil and the US comes close to the opposite of the relationship between Shell and the Netherlands. Social demand in the US has not created any pressure or provided sufficiently interesting market opportunities to ExxonMobil. Public concern for climate change has been relatively low and the environmental movement has not placed any strong pressure on the climate strategy of ExxonMobil in the US. This may also be related to a widespread perception of ExxonMobil as a 'super-tanker', insensitive to public pressure due to its size and power. Equally important is the North Americans' reluctance to pay a higher price for clean energy. Likewise, US supply of climate policy has been marked by lack of pressure and opportunities. US climate policy has been based on public voluntary programmes in which the industry has been invited to participate. These programmes aim to stimulate markets for energy-effective technologies, but ExxonMobil has not paid much attention to them. Genuinely voluntary programmes are most likely to work in a different 
social context marked by a higher social demand, such as the Netherlands.

The US political institutions linking state and society have traditionally been adversarial. ExxonMobil has brought this tradition further, as one of the leaders of the US fossil-fuel lobby, by lobbying forcefully and apparently successfully against the climate initiatives of the Clinton-Gore administration from 1993 to 2000. The relationship between the oil industry and US government has in this period been marked more by a state of Cold War than by constructive cooperation. In short, the link between the US and ExxonMobil's reactive climate strategy is marked by a negative interplay between pressures and market opportunities. Social demand for climate policy has been weak, governmental supply of climate policy has been weak, and the US political system is based on an adversarial approach that has stimulated a reactive strategy against the initiatives taken by the US administration in the 1990s. According to the DP model, the climate strategy of ExxonMobil can be understood as a combination of various domestic factors pointing in the same direction. In addition, the US context is marked by an interplay between political context and company-specific factors: ExxonMobil was in a way predisposed to a reactive strategy to a more significant extent than Shell and Statoil (see chapter 4).

This being said, ExxonMobil's strategy also leaves us with uneasiness against the backdrop of the DP model. The main cause for worry is again related to change: ExxonMobil did not show any signs of changing its climate strategy between 1997 and 2001. In this period, the US had signed the Kyoto Protocol demanding a dramatic change in US climate policy. The principal US architect behind the deal struck in Kyoto was Vice-President Al Gore, running against Bush for presidency in the autumn of 2000. While ExxonMobil and the rest of the US fossil-fuel lobby controlled domestic climate initiatives, the international process exposed ExxonMobil to significant uncertainty over this four-year period. In addition, the European market is also important to ExxonMobil (see chapter 3). A likely response would thus be to prepare for the worst case - a Kyoto Protocol in force including the US - but there is no evidence that ExxonMobil had a 'plan B' in the case of US ratification.

The relationship between Statoil and Norway appears more 
clear cut. The reason is not that Statoil is partly owned by the Norwegian state, but rather the high degree of overlap between Norway and the Scandinavian countries and Statoil's main markets. In Norway, social demand for climate policy has fluctuated significantly over time, thus generating quite ambiguous market signals. Statoil has been exposed to some pressure from ENGOs, but has not experienced large-scale consumer campaigns linked to any aspect of the company's activities. Norwegian climate policy has also been ambiguous. Targets on GHG emissions have been adopted, abolished and readopted, and Norwegian policy on renewables has not provided any strong incentives for Statoil. On the other hand, Norway was one of the first countries to adopt a $\mathrm{CO}_{2}$ tax, which applied specifically to the Norwegian continental shelf. This tax influenced the realisation of Statoil's $\mathrm{CO}_{2}$ programme, which aimed to increase energy efficiency. Statoil played the key role in the MILJØSOK initiative aimed at identifying solutions and improving environmental cooperation between the state and oil companies. MILJØSOK has also been seen as an important explanation for Statoil's climate strategy. In short, Statoil's ambiguous climate strategy appears closely linked to an ambiguous Norwegian climate policy context.

This chapter has provided some additional answers, but also raised new questions - particularly related to the conditions triggering change in the climate strategies of the oil companies. Why did ExxonMobil not modify its reactive strategy after the US consent to the Kyoto Protocol? And was Shell's turnabout caused exclusively by changes in the Dutch political context? In the next chapter, we explore these questions by analysing developments on the international level. We thus move beyond the analysis of single companies within single home countries to improve our understanding of changes in corporate climate strategies in particular. Our main assumption is that additional answers can be found at the interface between corporate influence on international regimes and regime influence on corporate strategies.

\section{Notes}

1 'Esso says effect of UK protests not yet clear'. Source: www. planetark.org (accessed 5 December 2001).

2 Source: www.statoil.com (accessed 28 March 2001). 
3 Personal communication with Barend van Engelenburg, Ministry of Housing, Spatial Planning and the Environment, 28 November 2000.

4 See Rowlands, 2000, for comparisons of national attitudes to climate change.

5 Results from 39 different reports focusing on this issue have been collected and analysed by the Ministry of the Environment. Twice a year since 1980 the research agency NSS/market onderzoek has measured the level of involvement among the Dutch population with regard to some 40 social issues.

6 It is important to emphasise that there are a number of methodological problems related to the measurement of citizens' willingness to pay. The results obtained from such analyses may depart significantly from actual consumer choice.

7 However, environmental problems related to air, water and soil rank higher in public awareness than do energy issues and climate change.

8 Personal comunication with Ir. Henk J. van Wouw, Shell Netherlands, 29 November 2000, and Barend van Engelenburg. Ministry of Housing, Spatial Planning and the Environment, 28 November 2000.

9 This study is based on lead news stories on 'global warming' in the New York Times and the Washington Post.

10 Personal communication with Brian P. Flannery and Gary F. Ehlig, ExxonMobil, Irving, Texas, March 2000.

11 Personal communication with Iain MacGill, senior policy analyst, Greenpeace Climate Campaign, Greenpeace, Washington, DC, 23 March 2000.

12 The MORI poll sampled 998 adults in 191 places across Great Britain. The results show that the share of customers that regularly bought petrol from ExxonMobil subsidiary Esso was reduced from 26 per cent in August 2001 to 19 per cent in July 2002. The share of customers that bought their petrol from Esso's rival retailer, BP, rose from 18 per cent in 2001 to 21 per cent in 2002. According to the head of environmental research at MORI, the change was 'statistically significant, beyond the margins of error'. (Source: www. planetark.org (accessed 5 September 2002).

13 Election data are not very robust, since environmental attitudes connected with elections are closely linked to the political context of each election.

14 Norsk Monitor is conducted by the Norwegian polling agency MMI (Markeds og Mediainstituttet). The data are an extension of those used in Norsk Monitor, based on communication with Ottar 
Hellevik, Director of MMI.

15 Stavanger Aftenblad, 28 January 2000, 'Statoil trekker seg fra vindkraftprosjekt' ('Statoil withdraws from windpower project'). Source: http://aftenbladet.no/nyheter/okonomi/article.jhtml? articleD=5730 (accessed 19 September 2002).

16 Aftenposten, 1 December 2001, 'Natur og Ungdom Anmelder Esso' ('Natur og Ungdom [the youth organisation of Naturvernforbund] starts lawsuit agaisnt Esso').

17 A study of the causes of climate policy would require an in-depth analysis of factors such as energy-economic circumstances, change in government and the position of the ruling party, governments' control over the legislature, distribution of competence between regulatory agencies, and different regulatory styles embedded in national history and tradition.

18 To enter into force at least 55 countries will have to ratify the Kyoto Protocol. In addition, the protocol has to be ratified by Annex I countries accounting for at least 55 per cent of the total $\mathrm{CO}_{2}$ emissions from Annex I countries in 1990.

19 The climate policy of the US was in this period developed in two documents. First, 'America's climate change strategy: an action agenda' was presented at the first INC session. Second, 'The US national climate change action plan' was presented at the sixth INSC meeting.

20 Other key elements underlying the US position were: (1) reluctance about additional financial support to developing countries to meet their obligations; and (2) ambition to create a strong but flexible international regime.

21 These concepts are borrowed from research primarily focusing on implementation of national policy. However, they are also applicable to joint international commitments. For example, one factor that distinguishes between them is whether the initial focus is a central governmental decision (top-down) or a network involved in a policy area (bottom-up). See e.g. Sabatier, 1986.

22 For example, in 1996 and 1997, only 60 per cent of the funding requested by the president was approved by Congress (Brunner and Klein, 1998).

23 Emissions increased by 14.5 per cent between 1990 and 2000. Adding the 7 per cent reduction Kyoto target, the US would have to reduce emission by 21.5 per cent before 2012 even in the absence of the expected annual increase in emissions.

24 'President announces clear skies and global climate change initiatives. Source: www.whitehouse.gov/news/releases/2002/02/20020214-5.html (accessed 15 February 2002). 
25 See DSP, 1997, for a description of the various programmes.

26 Personal communication with Brian P. Flannery and Gary F. Ehlig, ExxonMobil, Irving, Texas, March 2000.

27 This EPA-run programme seeks to encourage natural gas companies to adopt cost-effective technologies that reduce emissions of methane. The programme includes transmission, distribution and production (the last after 1995). The EPA provides implementation support, public recognition and removal of unjustified regulatory barriers, and the programme has identified various methane-reducing best-management practices. Participating companies submit a plan to the EPA, and implement it over the next three years.

28 Source: www.epa.gov/gasstar/annual.htm (accessed 29 October 1999).

29 Climate change may have striking consequences for the one-third of the Netherlands lying below sea level.

30 Also in 1990, the Rijkswaterstaat published the 'Impact of sea level rise on society' report. This concluded that the sea level may rise 60 $\mathrm{cm}$ per 100 years and the need for measures would become urgent from 2000 (Schenkel, 1998).

31 Fiscal incentives are provided by a number of provisions in corporate income tax: energy conservation and renewable energy are encouraged by these, and a tax credit was introduced in 1996.

32 Personal communication from Ir. Henk J. van Wouw, manager of environmental affairs, Shell Nederland BV, 28 November 2000.

33 The Dutch strategy was developed before the presidency period, and rested on two main principles. First, a sector approach was followed rather than a country-by-country one in calculating reduction potential. Second, the total EU target became directly linked to the size of national contributions to this target.

34 While the Kyoto protocol includes six GHGs, the EU agreement covers three substances: $\mathrm{CO}_{2}$, methane and $\mathrm{N}_{2} \mathrm{O}$.

35 This target was made conditional upon international and technological developments as well as further research.

36 Note that even though the reduction of domestic emissions is given the highest priority, the proposed climate package is expected only to cause emissions reductions of about half the expected rise of $\mathrm{CO}_{2}$ emissions.

37 'Norway to start emissions quota trading in 2005'. Source: www.planetark.org (accessed 25 March 2002).

38 Utilisation of bioenergy and water-carried central heating should be increased by 5 TWh over a period of $5-10$ years, representing about 5 per cent of total power production.

39 "'Hot air" blows gaping hole in the emissions trading scheme', 
ENDS Report, 326: March 2002.

40 Environmental Research and Analysis, US Department of Energy Office of Fossil Energy. Source: www.fe.doe.gov/oil_gas/oilgas7.html (accessed 15 April 1999).

41 Personal communication with Phil Cooney and Bill O'Keefe, API, 21 March 2000.

42 Personal communication with Phil Cooney and Bill O'Keefe, API, 21 March 2000.

43 The US Constitution was designed to demarcate power between the three branches of the federal government: the legislature, composed of the House of Representatives and the Senate, which together make up the Congress; the executive branch, including the president and federal agencies and departments; and the judiciary, consisting of federal courts.

44 New York Times, 27 March 2002, 'Documents show energy officials met only with industry leaders'.

45 'Bush energy plan said to help industry, not public'. Source: www.planet.ark.org (accessed 24 January 2002).

46 New York Times, 27 March 2002, 'Documents show energy officials met only with industry leaders'.

47 Personal communication with Barend van Engelenburg. Ministry of Housing, Spatial Planning and the Environment, 28 November 2000.

48 Personal communication with Ir. Henk J. van Wouw, manager of environmental affairs, Shell Netherlands, 29 November 2000.

49 Personal communication with Valèrie Callaud, EUROPIA, 30 November 2000.

50 Voluntary agreements have mainly been used in order to combat GHG emissions from the aluminium industry. 